\title{
Effects of the Building Code on Construction and Design of Hong Kong Residential Buildings in the Colony
}

\author{
Wong Wah Sang \\ University of Hong Kong, Hong Kong SAR
}

\begin{abstract}
This paper discusses the effects of the Building Ordinance and its allied regulations to control buildings during the colonial period of Hong Kong and how these actually determined to certain extent the form of buildings especially for residential type of development. Various introduction of the building code at different times were used to illustrate the different effects and building forms created by the control in high density urban environment. Volumetric control and floor area control had been tried in the city with different construction of buildings developed. The paper concludes with the remark on possible new vision for building control in the modern high density city.
\end{abstract}

\section{Background}

\subsection{Inroduction}

The people of Hong Kong in the days of the colony (1841-1941, 1945-1997) had to live in an environment of high density due to the shortage of flat buildable land and the continued increase of population through immigrants coming from Mainland China. Hence, because of physical environment and political decisions, high density and even overcrowding was the common way of habitation. However, this led to problems of health and safety as evident with recurrent disasters of plague and fire spreading. Hence regulated control of the built environment by the government was a must and eventually determined the conventional form for the residential buildings.

The first type of control in the late ninetieth century looks at basic means of health and safety through both the building code and the lease to separate buildings and limit urban development. As building technology progressed in the twentieth century, the construction of high-rise buildings were then possible and the building control was focused at three-dimensional forms for sufficient light and open space. However, the building forms following the limitations of the ordinance are still evident even with more modern residential buildings.

\subsection{A historical research analysis}

To investigate into the relation between the physical buildings and the building code, the research methodology is to reveal all the ordinance and allied regulations issued by the Hong Kong government in the period of the colonial rule of Hong Kong and see how the physical forms such as building height, building features and floor plans of buildings have been affected by the legislative control. Due to the need of maximization of the developable space or floor area, the buildings have to conform to an imaginative mold set up by the building code. Hence, similarities in the external form and floor plans of buildings is the result of such building control.

Throughout the history of Hong Kong as a colony for about one and half centuries, the control of building development through various forms of Building Ordinances did occur. These ordinances have been changing because of the various human needs had changed, the advancement and development of building technologies and also the gradual cultural changes in the society. By revealing the different building code at various times and mapping it with the appropriate buildings at that time, the control on building form through the building code has been found to be obvious and evident to create physical architectural forms that have been distinctive of certain time and place.

Before going to the historical evolvement of the Building code, we have to see the most important background, i.e. the formation of high density in the colony.

\subsection{Building in high density}

According to the Census and Statistics Department, we notice that the land population density in Hong Kong at mid-2012 stood at 6620 persons per square kilometer. However, there are slopes and hills which remain green in Hong Kong so that the total built-up area accounts to less than one quarter of the total land area. Hence the actual average density should work out to be like 26,000 persons per sq. km. Kwun Tong, our most densely populated area, had 56,200 persons per kilometer [1]. Compared to the 
rest of the world, Manila has a density of approx. 43,000/sq. km., Paris approx. 22,000 and Cairo approx. 18000 .

Briefly, the answer to this when we trace back our history [10] can be in three folds: increase of population, lack of land supply and limited knowledge of building technology. Population at 26 January, 1841, when the Union Flag of Britain rose at Possession Point of Hong Kong Island was 7,450 but later the census of 1865 recorded a population of 125,504 . However, land had never increased in the same rate with population and we can see the hilly Hong Kong Island had not encouraged any means of easy construction. Hence, low-rise buildings were mainly built and confined to the coastline or as merely supported by stilts on slopes. (Figure 1).

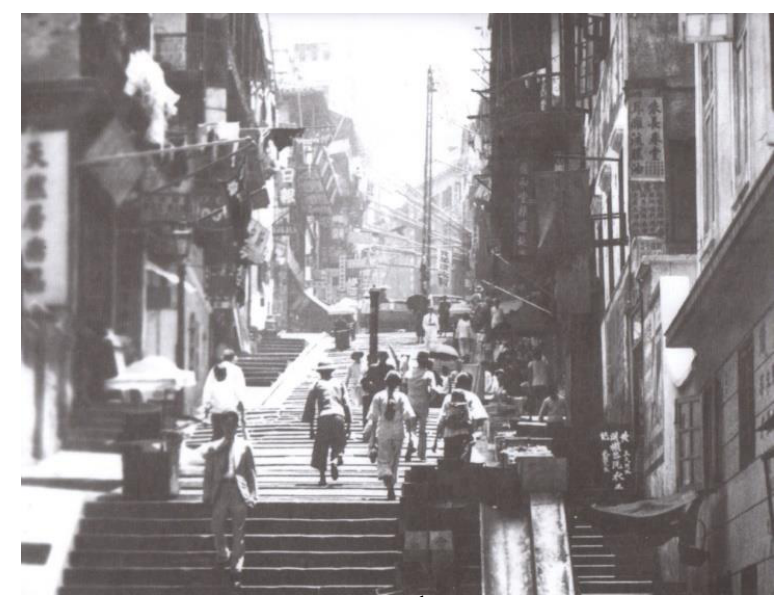

Figure 1. Potting Street in late $19^{\text {th }}$ century.

People lived in the type of residential buildings called the "Tong Lau" [11] (figure 2) which were tenement houses with both Chinese and European characteristics. These are usually constructed of loadbearing brick walls supported timber and later concrete floors. Four storeys are the common limit of the building height. Each storey would be bounded by two side walls (called party walls) with windows only at front or back and then the long space is sub-divided into rooms with cooking and toilet facilities at the back. High density is created by the placing of these houses side by side, sharing the loadbearing wall to form row houses. Verandahs are common features which form extension of these buildings onto the pedestrian street. (Figure 3) The urban effect of this type of building can still be seen its five-meter modules of the previous façade along many streets with re-new developments. Fire and plague form two evils to this kind of residential accommodation as both can spread easily through the side-by-side houses.

\section{The building code}

\subsection{Setting up of buildings ordinance}

To look at the safety and health issues associated with such urban living, the first code was set up by the Hong Kong Government in 1856 [3] and was called the
Ordinance for Buildings and Nuisance. Within this legislative control, terms for walls, storeys, buildings were defined and construction technique and materials were regulated. You may be surprised by the use of "Nuisance" in the ordinance. The nuisances mean the verandahs in poor state of care, buildings in ruinous and dangerous conditions, unauthorized building works, building parts erected with inflammable materials contravening the Ordinance etc. These are called nuisances because they can become causes of fire and unhygienic conditions. As this is written in the ordinance, it is probably a common phenomenon at those days.

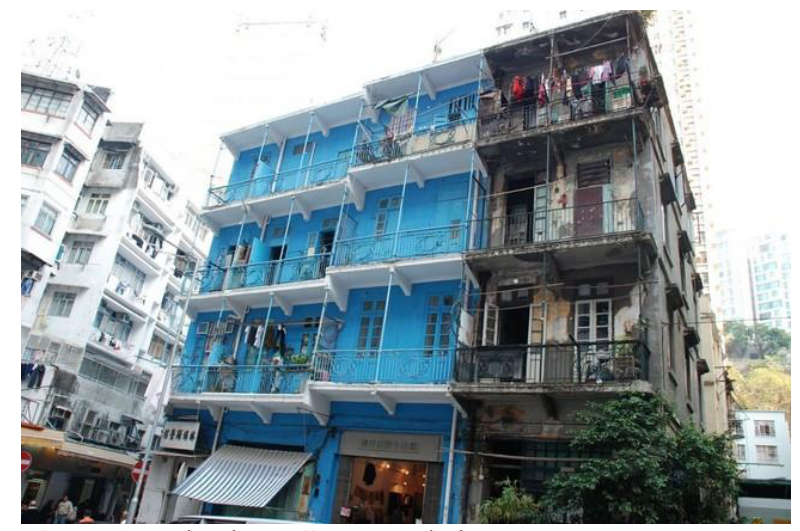

Figure 2. "Blue house" at Wanchai.

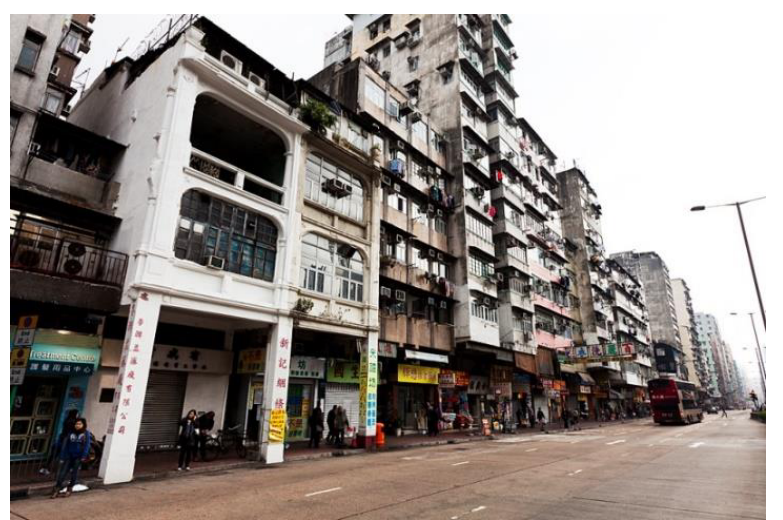

Figure 3. Buildings at Shanghai Street.

Despite the control of high density through law, the demand for habitation continued as more people settled in Hong Kong from China such that plaque and fires did frequently occur. The issue for shortage of land supply was then partly resolved by reclamation - transforming land from the sea. And in 1868 the first coastal reclamation project (Praya Reclamation Scheme) [12] started to form at 1873 the present Des Voeux Road in Central. (figure 4) The British expert asked by the Colonial government to make recommendations on the urban situation in 1882 was Usbert Chadwick. Subsequently, the Ordinance was revised again and again. In the 1889 Buildings Ordinance, the limit of building height was set to 76 feet.

With continued increase in population, health was constantly a problem. Plaques broke out quite frequently so that in 1894, the Tai Ping Shan Resumption Ordinance gave authority to re-build 10 acres of the most unsanitary land. Health issues also led to the formation of the Public 
Health and Buildings Ordinance in 1903 [4]. Here we have a definition for overcrowding of a domestic building written as "in excess of a proportion of one adult for every fifty square feet of habitable space or superficial area and five hundred and fifty cubic feet of clear and unobstructed internal air space".

In this 1903 Ordinance, the bye-laws list the construction of opium divans with standards of ventilation, drainage and opening hours. Yet in 1909, International Opium Conference was held at Shanghai to discuss the restriction on the sale of harmful drugs. Subsequently in 1910, all opium houses in Hong Kong were closed down.

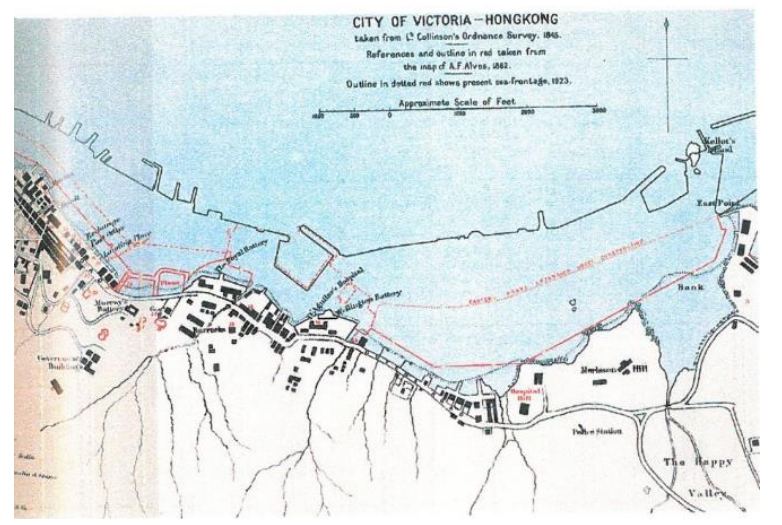

Figure 4. Map of Central in late $19^{\text {th }}$ century.

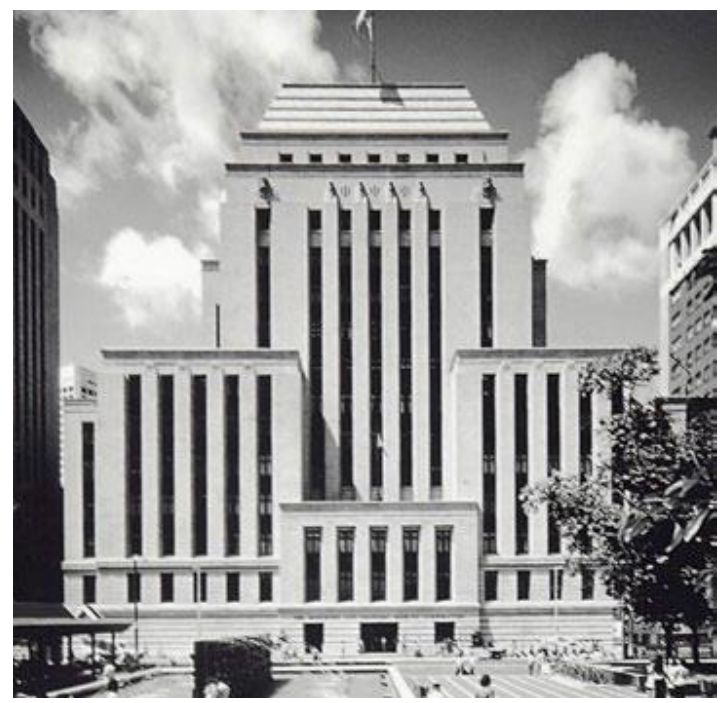

Figure 5. The Hong Kong and shanghai Bank Headquarters in 1935

\subsection{Constructin of tall buildings in twentieth century}

At early twentieth century, reinforced concrete was introduced to the construction technology of Hong Kong. An example is the Hong Kong and Shanghai Bank (Figure 5) completed in 1935 October with a building height of 217 feet and 14 storeys. To cater for the technology advancement that brought increase of population density on a piece of land, the control of building was enacted as the 1935 Buildings Ordinance [5]. The main points of concern here are the minimum clear height of a floor to provide for sufficient lighting and ventilation, standard for the tread and rise of a stair to cater for fire escape, fire resisting door construction to hold up fire, minimum area for kitchen to secure a safe cooking place, minimum required opening for windows to allow for lighting and ventilation and provisions for open spaces for domestic (residential) buildings to allow adequate space around the building. To follow on this, the height of buildings was also controlled in relation to the adjacent street width. (Figure 6).

Following World War II was a period of intense building. The population was recorded to be 2.5 million at 1950. Fires got more serious and in 1953, a fire at the squatters of Shek Kip Mei (Figure 7) left 50,000 people homeless. Such were the background to bring about the establishment of the Housing Authority to look at public housing and the new Buildings Ordinance of 1955 to control private residential development. The statistics at 2012 reveals that $52.8 \%$ population lived in private housing, $29.7 \%$ public rental housing, $17.0 \%$ subsidized home ownership housing and $0.5 \%$ temporary housing. We can see both private and public sector play equal contribution to the residential living in Hong Kong.

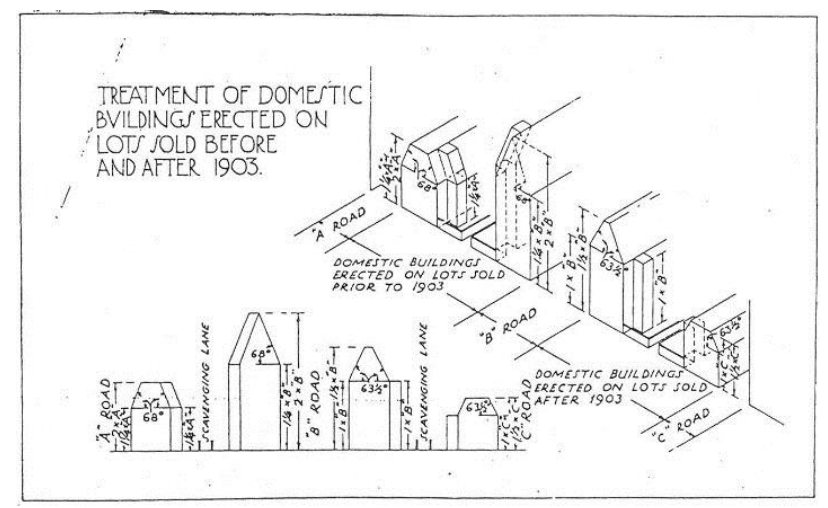

Figure 6. Control of building height based on street width.

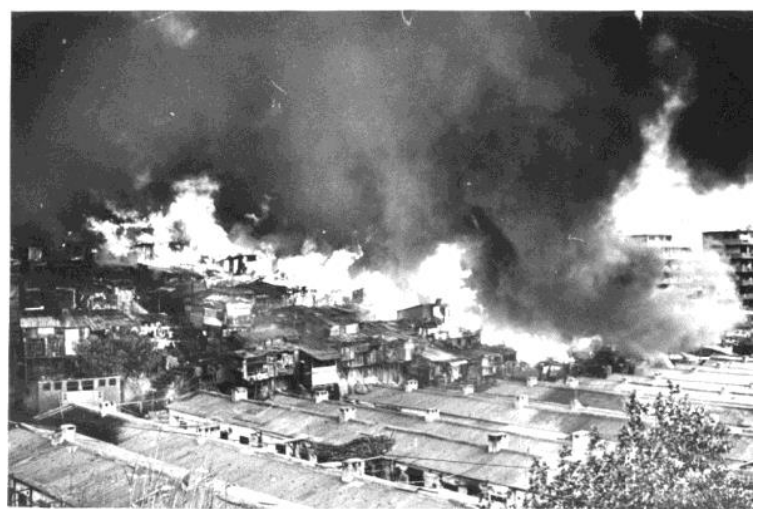

Figure 7. Fire in Shek Kip Mei Xmas 1953.

\subsection{Construction of buildings enforced by the ordinance}

The high-rise era of Hong Kong began in the period of 50 s to 70s with development of New Towns. At the same time, the very important Buildings Ordinance at 1955[6] established the basis of building development and control in the years following up till the present. The design and 
planning layout of buildings are controlled in terms of projections from buildings, building heights, volumes and open spaces, windows for lighting and ventilation, sanitation, staircases for fire escapes etc. Also, the construction of buildings was regulated with materials, structural loading, foundations, roofs, chimneys, fireresisting construction, retaining walls, plumbing and drainage as well as lifts and escalators. (Figure 8).

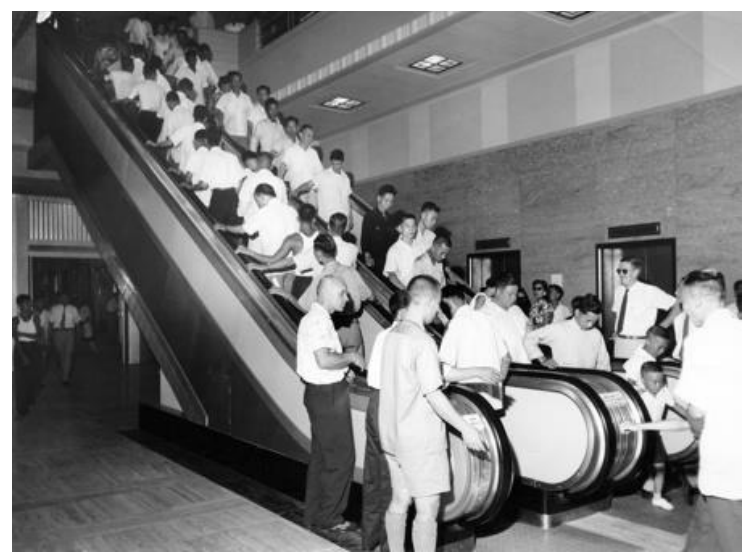

Figure 8. Escalator in Man Yee Building of 60s.
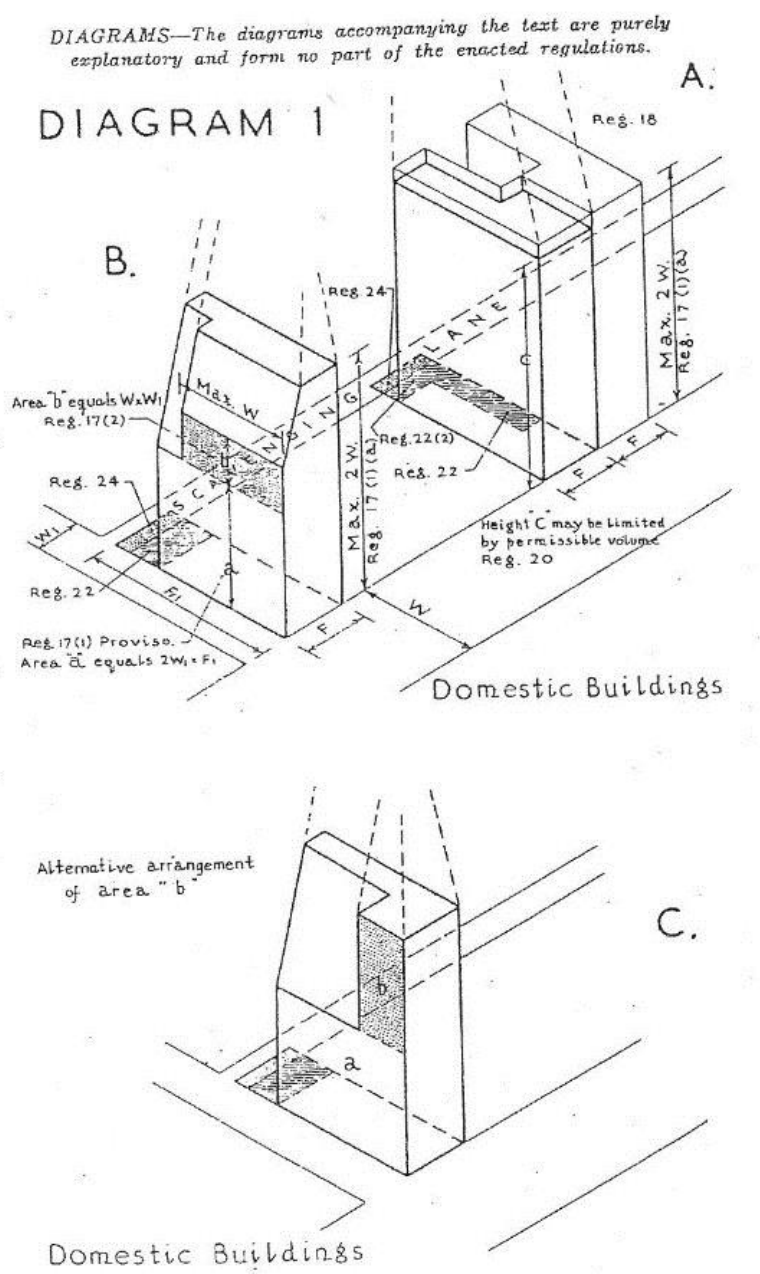

Figure 9. Setback of buildings in 76 degrees.

To clarify the control systems, the Buildings Ordinance was further divided into Building Regulations in three aspects of administration, planning and construction in 1956. The administration regulations take care of government procedures for approval of plans and permission for construction and occupation by users. The planning regulations oversee the design and layout of the buildings. The construction regulations look at the minimum standards of building materials and technology. And then subsequently regulations relating to demolition, sanitary provisions, private streets, refuse storage, lifts and escalators etc. were enacted.

The street adjacent to the building was made as a reference to development density control. The building bulk was related to the width of the street to allow adequate light and ventilation into the building. Briefly, it is based on "The wider the street, the higher the building." Setback of 76 degrees (ratio of 1:4) on the mass of the buildings was allowed and this molded the resultant building form like stepping pyramids (Figure 9). Then balconies and canopies over streets were also calculated with reference to the width of streets.

Restriction on the building bulk was also effected by the regulations on staircases and fire escapes. The riser height with maximum of 7 inches and the maximum of steps in one flight as 16 add up to 112 inches or 9 feet 4 inches. This is equivalent to the addition of 4 inches of structural slab plus about 9 feet as headroom of the internal space. Hence, if you need more headroom, you have to build more steps and an intermediate landing to maintain the maximum number of steps. Despite these high-rise developments, tenement houses still existed at that time and received more relaxed standard of control (Figure 10).

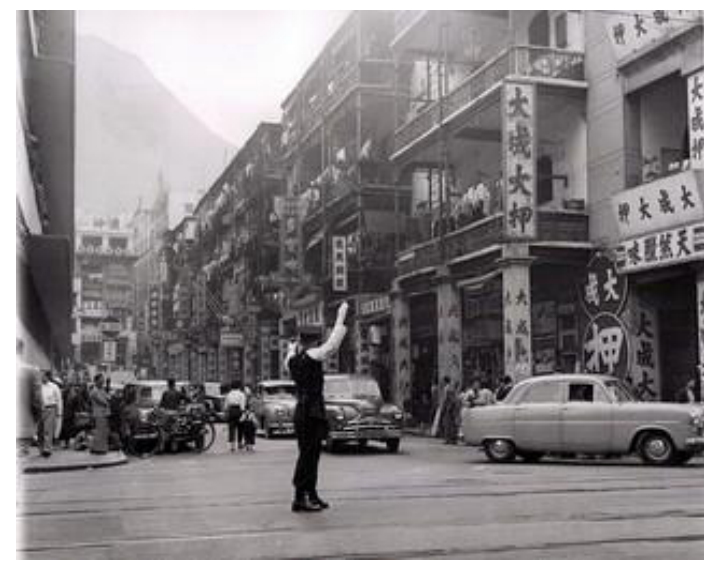

Figure 10. Post-war tenement houses.

A party wall is a common wall which supports two tenement houses or Tong-Lau. It also symbolizes ownership of the land because the site boundary actually lies in the middle of it. This poses a problem when the land owner decides to demolish the existing Tong-Lau, he cannot take down the party wall otherwise the adjacent Tong-Lau will collapse. And then subsequently, when the adjacent land owner wishes to demolish his building for development, he also cannot take down the party wall unless he got the agreement from all the individual owners of the new building next to him. As a result, these party walls become historical relics in the modern city.

\subsection{Control of developable volume}


An illustration of the control by volume for buildings can be seen in an example of a 1960s apartment building in Causeway Bay (Figure 11). The site area is approx.. 6200 sq. $\mathrm{ft}$. and the resultant residential had got a ground floor of shops and then 13 floors of residential flats accumulating a total of 66000sq.ft. in floor area and approx. 645000 cubic $\mathrm{ft}$. in volume. The building was a bulky development seemingly occupying the whole site and even more with projections of windows over the street and the upper floors with a 76 degree stepping form (Figure 12). This mode of development control actually generates the largest bulk of building.

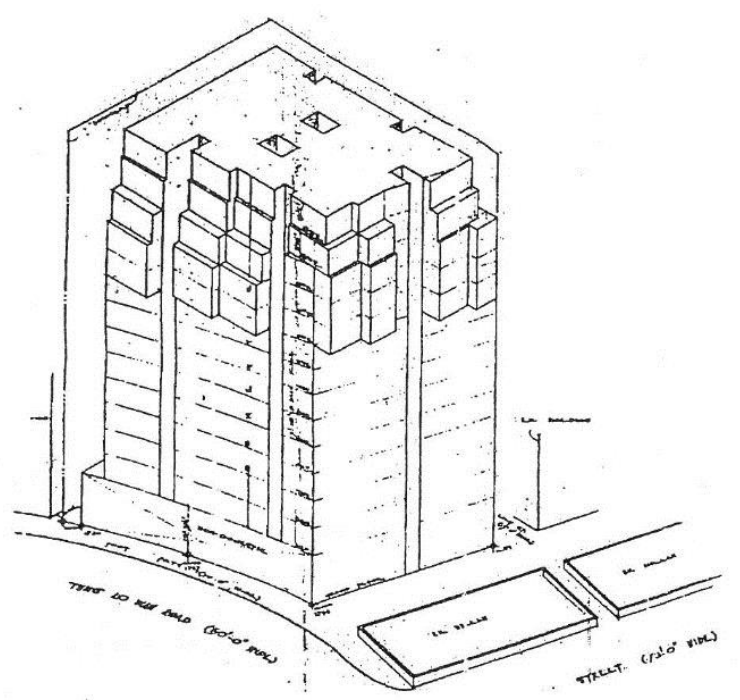

Figure 11. Apartment building in $60 \mathrm{~s}$.

Further categorization for building control can be seen in the 1962 Building (Planning) Amendments regulations. The notion of "plot ratio" and "gross floor area" were introduced. The gross floor area means the area enclosed by the external wall at each floor while the plot ratio is defined as the total gross floor area of a building divided by the area on which the building is erected. The plot ratio depends on the type of site which was defined in three classes. Class A means a site that abuts on one street; class B means a corner site that abuts two streets and class $\mathrm{C}$ means a corner site that abuts three streets or an island site surrounded by streets completely. (Figure 13) As a result of this, the more streets around you, the more you can build.

\subsection{Building typology in the ordinance and control of building forms}

Buildings were classified by the Ordinance into two types - domestic and non-domestic. One can imagine that domestic (residential) buildings with the population sleeping overnight will be more vulnerable to health and safety risks. The maximum plot for domestic buildings would work out to be 10 while that of non-domestic buildings is 15. Another important regulation clause to shape the urban environment is the permission of $100 \%$ site coverage in the first 50 feet height of the building (Figure 14). The appearance for execution of this clause virtually cut off all potential open space in the ground floor and left the city with only open spaces in the form of roads for vehicular traffic like vertical concrete canyons.

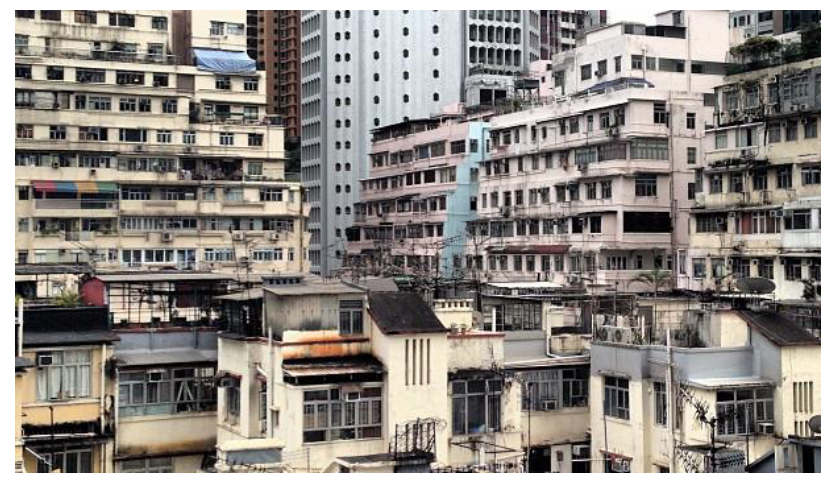

Figure 12. Buildings with setback at top.

FIRST SCHEDULE

Percentage site coverages and plot ratios.

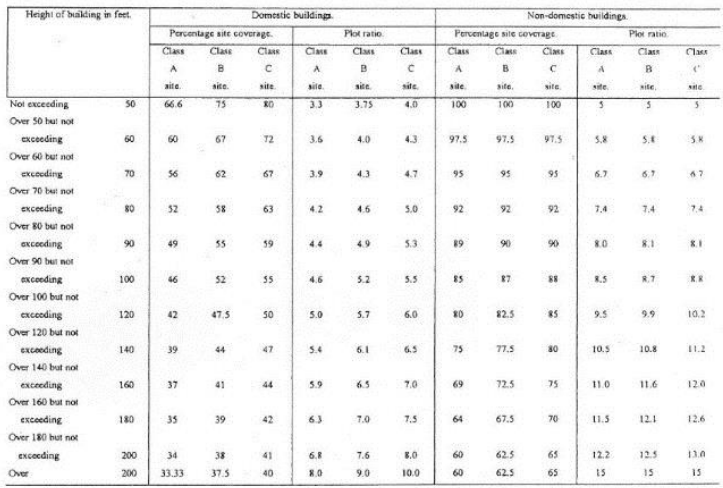

Figure 13. Schedule of site coverage and pot ratio.

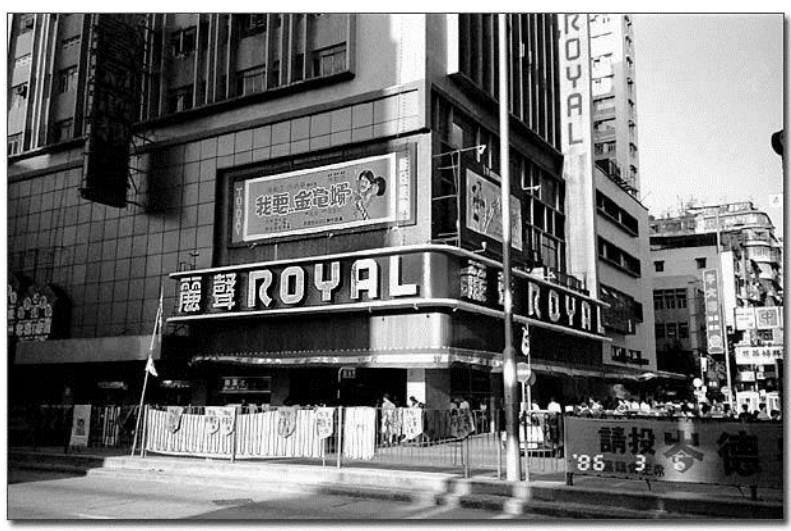

Figure 14. Podium of $100 \%$ site coverage.

Another control on building form was introduced in 1969 [7] as the "Street shadow area" through amendment on the building (Planning) Regulations. A formula of " $\mathrm{F} \mathrm{x}$ W/2" was the limit to the street shadow of a building was formed by projecting the building like with a 76 degree sun onto the street. Here $F$ is the width of the building frontage and $\mathrm{W}$ is the width of the street with the street shadow. The shadow was entirely mathematical and did not take into account the actual orientation of the sun. The 
result of this created buildings with the 76 degree sloping profile. This control created aesthetical effects generally not welcomed by the community and was later revoked. However, buildings (Figure 15) conforming to this control still remain.

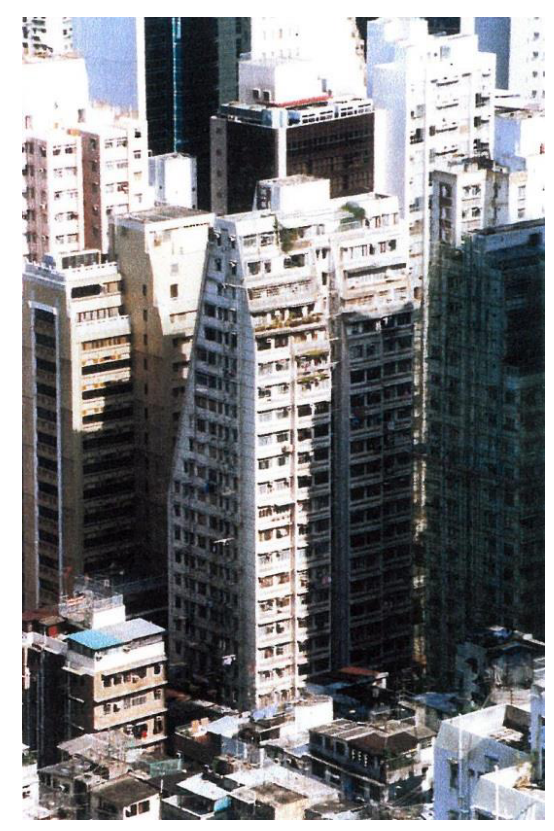

Figure 15. High-rise buildings with sloping profile.

Residential prices in Hong Kong soared throughout the years so that through continuous experience with the real estate market and the restrictions from the Buildings Ordinance and regulations the most efficient residential floor plan is produced. (Figure 16) This ideal plan places all the common area into the central core of the building and usually divided into eight flats[2]. The staircase is an overlapping pair of staircases called the "scissors staircase". And the building of multi-storeys is basically an extrusion of the typical floor plan (Figure 17).

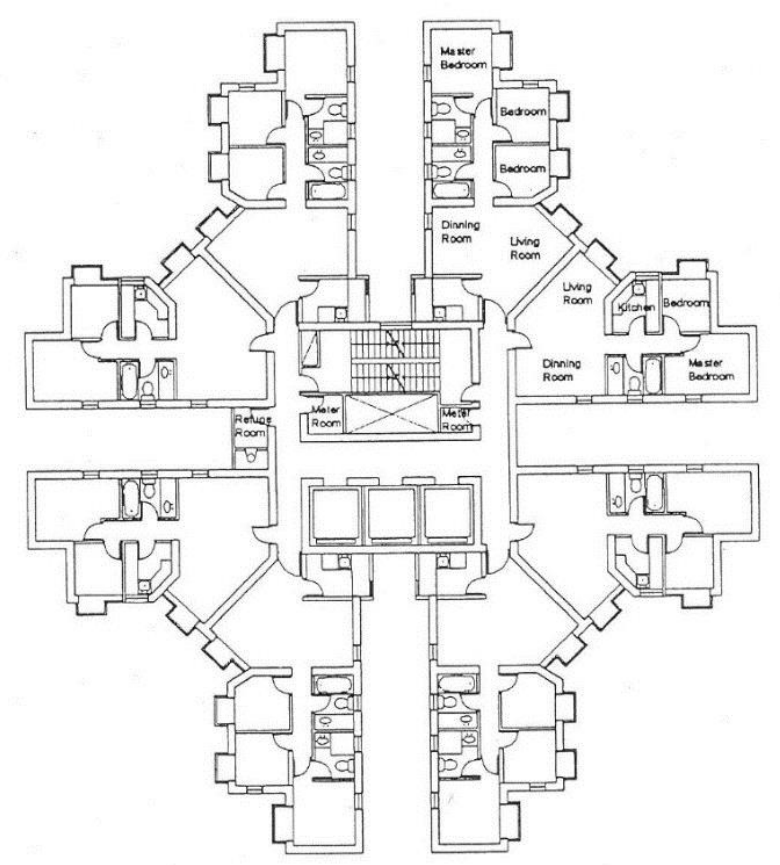

Figure 16. The floor plan with eight flats and central core.

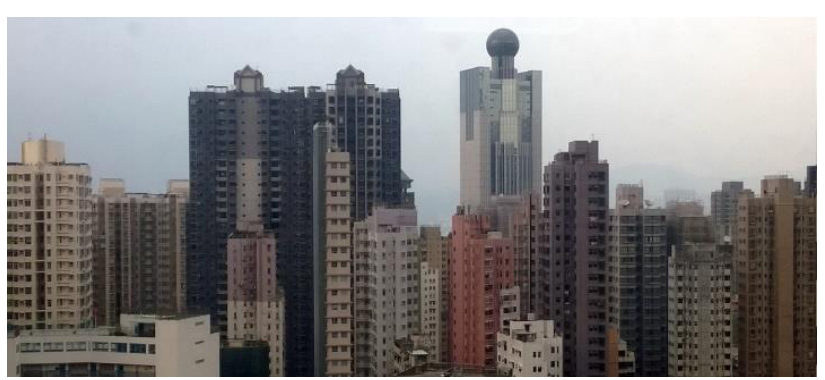

Figure 17. Buildings as extrusion forms of the floor plan.

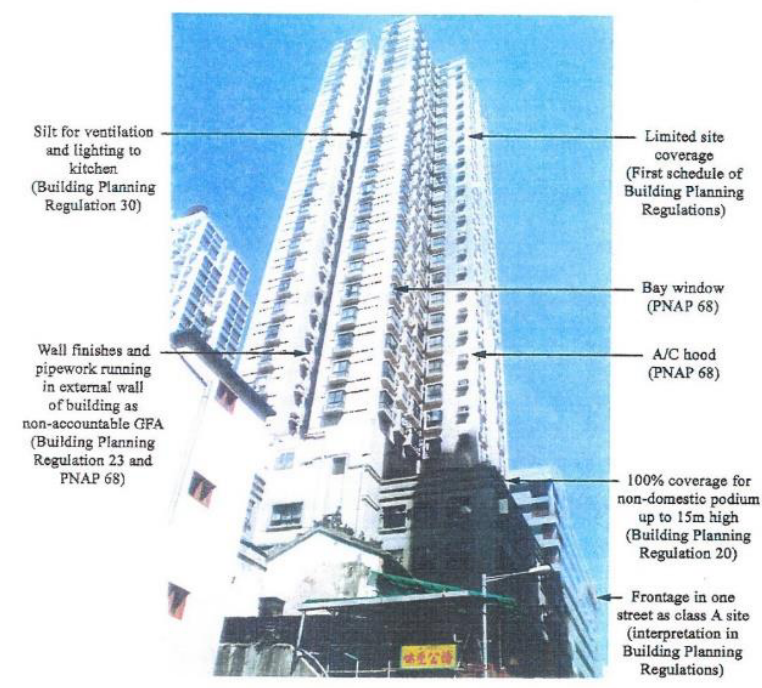

Figure 18. Typical building conforming to building code control.

The phenomenon of this floor plan can be revealed in further details. Projected windows called "bay windows" generally are assigned to each bedroom and living/dining room to enjoy the privilege of non-accountable floor area. Recesses on the floor plan called "re-entrants" are located to increase the length of building periphery as well as to provide windows for rooms especially the kitchen to satisfy the requirements for lighting and ventilation. And the whole tower may just rest on a $15 \mathrm{~m}$ high podium to suit the property market or not. This type of plan[8] flourished all the years with high-rise residential building developments (Figure 18) and well carried into years after the return of the sovereign to China in 1997.

\section{Final remarks and recommendation}

Through the years of colonization in Hong Kong from early years with Tong Lau to the high-rise residential development in early $21^{\text {st }}$ century, economy and efficiency has taken priority of development over other modern design parameters like sustainability, aesthetics, culture, computerization, etc. The control of development [9] is initiated through the government with the Director of the Buildings Department as the Building Authority. Initiation of building control rests with the government. The current methods of improvement and updating is still based on the basic 1955 Buildings Ordinance and regulations through modification, add-ons and amendments. As new technology from construction 
materials, building methods and computer engineering come about with social changes of working and living requirement, it looks that only with major change of the code can our living environment be varied and improved with a better holistic view of multiple issues.

This research study mainly has focus limited within the private residential developments in the history of colonial Hong Kong. Residential flats are called "domestic" in the building code while all other buildings are called "non-domestic". There is also a distinction between private and public residential buildings since private buildings are subject to control by the Buildings Ordinance and public residential buildings or housing are under the Housing Authority and do not require to be regulated through the formal procedure of the Buildings Department though they are still supposed to follow the building code. Hence forward research on this subject can be on public housing and non-domestic buildings to see how these building typologies have been influenced by the Building Ordinance and Regulations.

\section{References}

1. Buildings Department, "Building Development and Control in Hong Kong”, Hong Kong Government, 27-53 (1999)
2. Chan, H W, Tang, BS, Wong, WS, "Density Control and the quality of living space: a case study of private housing development in Hong Kong”, Habitat International, (2001)

3. Ordinance for Buildings and Nuisance in Hong Kong Gazette Note 12 of 1856

4. The Buildings Ordinance in the Hong Kong Government Gazette, (February 27, 1903)

5. The Buildings Ordinance in the Hong Kong Government Gazette, (April 12, 1935)

6. The Buildings Ordinance in the Hong Kong Government Gazette no. 68 of 1955.

7. The Buildings (Amendments) Regulations in the Hong Kong Government Gazette (1969)

8. Wong, WS, Legislative Control for Quality Buildings, HKIA Journal, 22, 20-32 (1999)

9. Wong, WS, "Legislation and Safety of tall Buildings" from High-rise Living in Asian Cities, Springer, 81112 (2011)

10. http://en.wikipedia.org/wiki/History_of_Hong_Kong _(1800s\%E2\%80\%931930s)\#Population

11. $\overline{\mathrm{http}} / / /$ en.wikipedia.org/wiki/Tong_lau

12. http://en.wikipedia.org/wiki/Praya_Reclamation_Sch eme 